TID-4500, UC-35

Nuclear Explosions-

Peaceful Applications

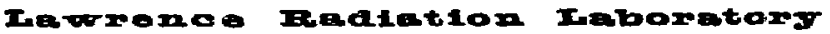

UIIUESITY OF CALIFORHIA

LIVERUARE

94550

UCRL-50993, Rev. 1

\title{
PREDICTION OF UNDERGROUND NUCLEAR EXPLOSION EFFECTS IN WAGON WHEEL SANDSTONE
}

\author{
Robert W. Terhune
}

\begin{abstract}
NOTICE
Thin mport wh propered as in eccount of wok ponered by the United Statea Govmment. Neither the United Shies aco the United Statec Atomie Eneng Commicion, nor eny of thet employeat nor any of theif contractors, mbeontractors, or their emptoyeas, males any werrinty, expres or inpliad or enumes any

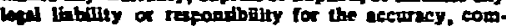

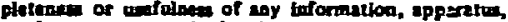

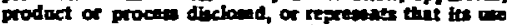
wortd not infinge petretely owned ridhte.
\end{abstract}




\section{Contents}

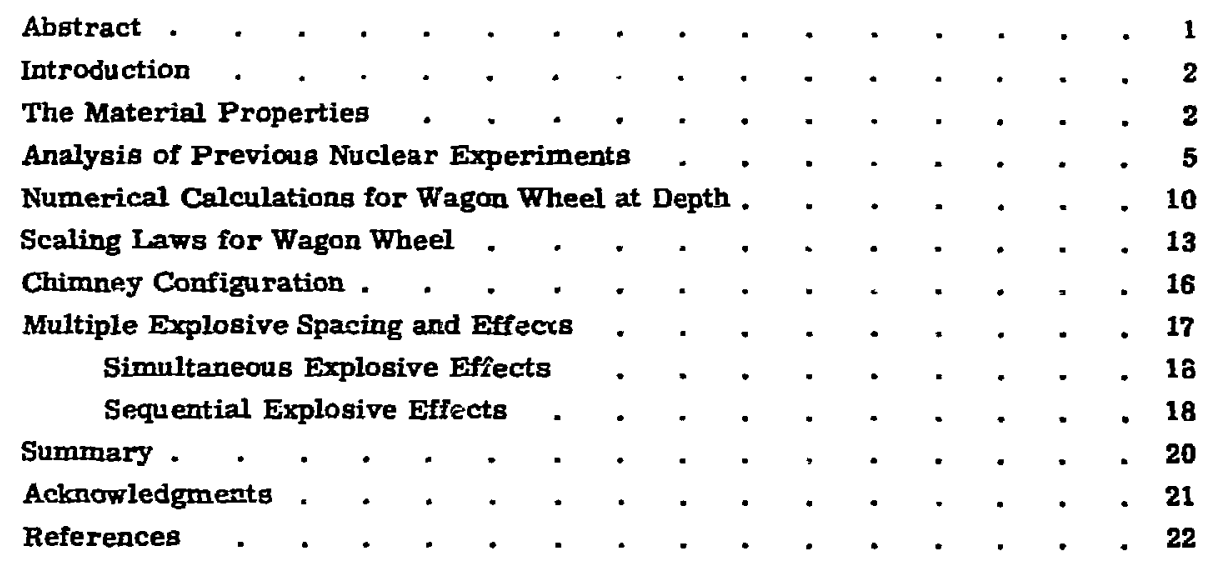




\title{
PREDICTION OF UNDERGROUND NUCLEAR EXPLOSION EFFECTS IN WAGON WHEEL SANDSTONE
}

\begin{abstract}
Project Wagon Wheel is a joint study by Lawrence Radiation Laboratory (LRL) and El Paso Natural Gas Co. (EPNG) to investigate the technical concept of mclear stimulation of a natural gas reservoir located near Pinedale, Wyoming. This paper presents the results of computer calculations, simulating the explosion effects, based on equation-of-state measurements of core samples taken from EPNG Wagon Wheel No. 1 hole at a depth between 8,000 to $12,000 \mathrm{ft}$.

The shear failure envelope for Wagon Wheel sandstone is almost identical to that for Hoggar granite. A calculation or Wagon Wheel sandstone for one-kt energy at a depth of $300 \mathrm{~m}$ duplicated cavity radiuB, shear fracture radius, stressed region, peak particle velocity, and peak acceleration data measured from the nuclear experiments conducted in the Hoggar granite by the French. The conclusion drawn from this comparison is that the Hoggar granite chimneys and regions of increased permeability provide a reasonable model to assume for Wagon Wheel.

A single explosive detonated at a depth of $10,000 \mathrm{ft}$ is predinted to produce a

cavity radius of $5.77 \mathrm{w}^{1 / 3}\left(\mathrm{~m}, \mathrm{k}^{1 / 3}\right)$, with shear fractures extending out to 2.5 cavity radii followed by a stressed region to 5 cavity radii. The expected chimney will have a radius of 1.2 cavity radii and a height of 2.5 cavity radii above the shot point, resulting in an apical void at the top representing about $50 \%$ of the cavity volume. Large increase in permeability is expected only within the region of shear fracture.

Chimnes height for multiple detonations is expected to be 4 cavity radii based on a rubble porosity of $21 \%$. Explosive spacing for multiple simultaneous detonstions varies from a minimum of 5 cavity radii (tangent chimneys) to 7.0 cavity radii based on maximum fracture increase due to shock interaction. Explosive spacing for sequential detonation varied between 7.5 and $\mathbf{1 2 . 5}$ cavity radius based on the similarity between cratering phenomenology (reflecting a shock from the ground surface) and reflecting a shock off the apical void of a previously formed chimney. It is expected that a permeable annular ring will form arcund the axis between the two exploaives to connect the lower chimney with the carity above.
\end{abstract}




\section{introduction}

Detonation of a deeply buried twclear explosive creates a stress discontimuity of tens of megabars which propagates into the surrounding media. This stress discontinuity (shock wave) deposits energy in the rock and is thus attenuated as it propagates radially from the gource.

Initially enough energy is deposited to vaporize the rock (approximately 70 tons of rock is raporized per kiloton of explosive energy); only enough additional energy is deposited from the outgoing shock wave to melt the rock out to about twice the radius of vaporization. Beyond this the rock is fractured until, at large distances from the source, the shock wave has decayed to a point to where it propagates elastically. The savity (formed by the vaporized region) expands until the pressure in the cavity is in equilibrium with the stresses in the rock. This equilibrium point is defined as the cavity radius $R_{c}$. By processes not well understood at the present time, the upper hemispluere of the cayity collapses. Once initiated, the collapse generally contimues rapicly until it is terminated by a natural arch or until the top is supported by the bulked rock. The collapsed region has been deacribed as the chimney because of its usual cylindrical shape, with the axis of gymmetry oriented perpendicular to the bedding. The height above the shot point at which collapse terminated is definet as the chimney height. The radius of the shimney may vary between 1 to 1.4 times the cavity radius.

Gas flow calculations ${ }^{1}$ have indicated that the most important parameters of the explosive effects to gas gtimulation are the chimney height, the chimney radius, and the horizontal extent of increased permeability. The increased permeability may correlate with the degree and type of fracturing in the fracture region.

The purpose of this paper is to predict the cavity redius, chimney height and fracture radius. Also, effects from sequestial and simultaneous detonation of several explosices will be estimated. The predictive techniques used (numerical calculations and scaling) require an extensive knowledge of the rock properties.

\section{The Material Properties}

Based on the properties of the gar, reservoir, the infervals selected for explosion effects prediction were from $9,000 \mathrm{ft}$ to 10,500 it and from $11,300 \mathrm{ft}$ to 11,800 ft where there were indications of gas in place. A cross section of these intervals showing the general stratigraphy, cored sections, and selected wire line logs is shown in Fig. 1 for the Wagon Wheel
Hole No, 1 located in the NE/ $/ 4 \mathrm{SE} / 4$ of Section 9, T-30-N, R-108W Sublette County, Wyoming.

Selected core samples were analyzed for their strength and cther mechanicai properties by LRL ${ }^{2}$ and Tera-Teis Inc. ${ }^{3}$ The Tera-Tek analysis (performed for EPNG) was limited to analysis of one sandscone sampie. The LRL tests were more 


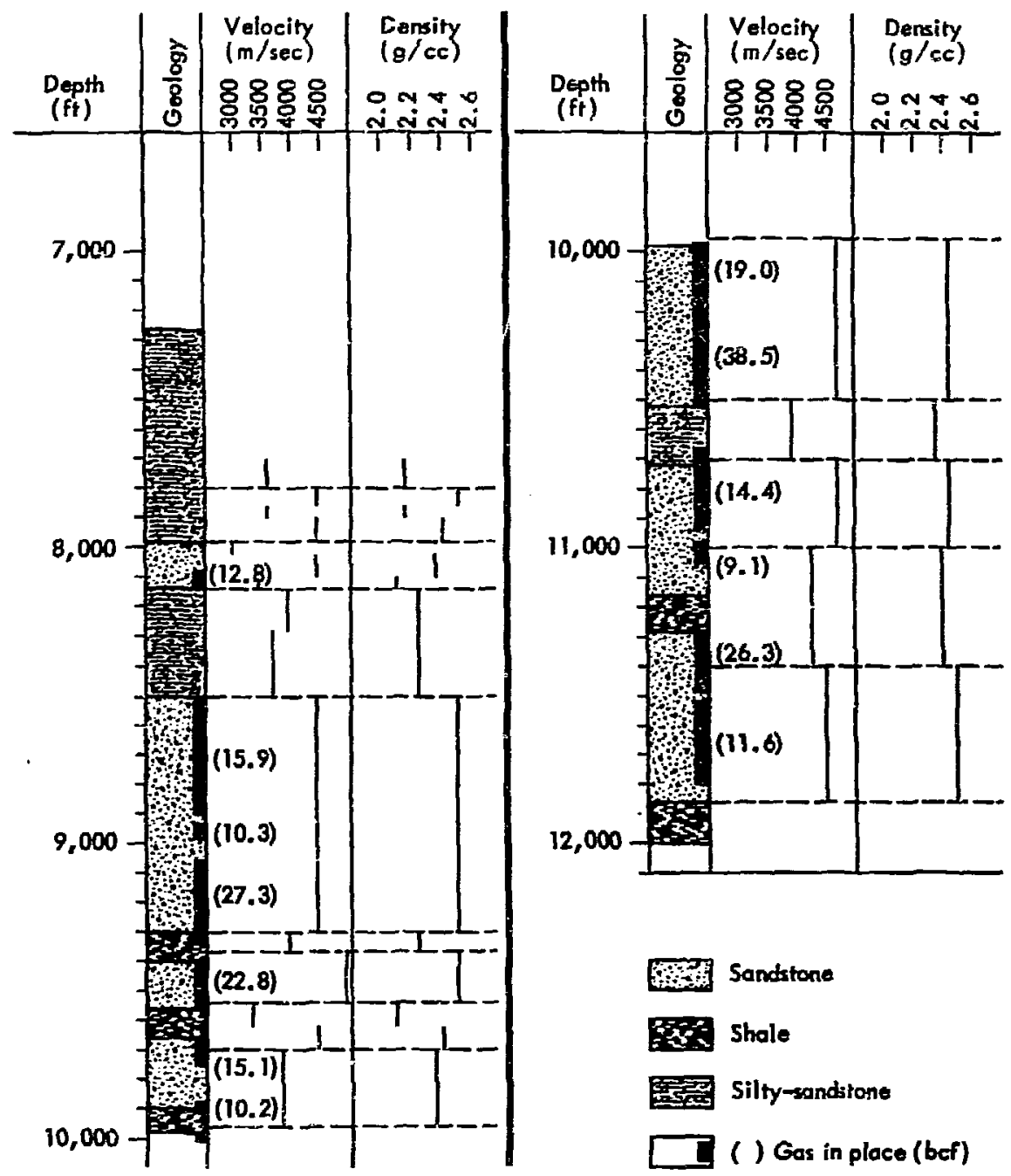

Fig. 1. Cross section of intervals selected showing the general stratigraphy cored sections, and selected wire line logs.

extensive and included tests on aamples from sereral locations. It should be noted that almost all tests by LRL and Tera-Tek Inc., were in excellent agreement, as were laboratory measurement of density and compressional velocity with the wire-line logs. Pressure-volume relationship to
40 kbar and the failure envelope are given in UCRL-50963, Fef, 2. Shook Fugoniat ${ }^{4}$ measurements are given in Table 1.

In the static tests it was also noted that in a pressure excursion up to 40 kbar and back to zero there was about $i \%$ irreversible compaction. 
Table 1. Results of the Shock Hugoniot Measurement.

\begin{tabular}{|c|c|c|c|c|c|}
\hline & $\rho_{\mathrm{o}}$ & $\mathbf{U}_{\mathbf{s}}$ & $\mathrm{U}_{\mathrm{p}}$ & $\sigma$ & $\mathbf{v}$ \\
\hline Wet & 2.474 & 7.44 & 3.35 & 617 & 0.222 \\
\hline Dry & 2.422 & 7.45 & 3.38 & 610 & 0.226 \\
\hline Dry & 2.425 & 7.49 & 3.37 & 612 & 0.227 \\
\hline Wet & 2.450 & 5.55 & 1.99 & 271 & 0.262 \\
\hline Wet & 2.440 & 5.50 & 2.00 & 269 & 0.261 \\
\hline Dry & 2.430 & 5.46 & 2.01 & 267 & 0.260 \\
\hline Dry & 2.430 & 5.53 & 2.00 & 269 & 0.263 \\
\hline Wet & 2.438 & 5.20 & 1.34 & 170 & 0.304 \\
\hline Wet & 2.451 & 5.16 & 1.34 & 170 & 0.302 \\
\hline Dry & 2.422 & 5.16 & 1.35 & 169 & 0.305 \\
\hline Dry & 2.398 & 5.17 & 1.34 & 167 & 0.309 \\
\hline & \multicolumn{5}{|c|}{$\begin{aligned} \rho_{0} & =\text { builk density in } \mathrm{gm} / \mathrm{cm}^{3} \\
U_{B} & =\text { shock velocity } \mathrm{m} / \mathrm{msec} \\
U_{p} & =\text { particle velocity } \mathrm{m} / \mathrm{msec} \\
\sigma & =\text { principal stress } \mathrm{kbar} \\
V & =\text { specific volume } \mathrm{cm}^{3} / \mathrm{gm}\end{aligned}$} \\
\hline
\end{tabular}

The driving pressure for the calcula-. tions was the cavity pressure-volume curve shown in Fig. 2. This curve is based on the $\mathrm{SiO}_{2}+1 \% \mathrm{H}_{2} \mathrm{O}$ gas equation-ofstate and adiabatic expansion relationship developed at LRL. 5

The calculation is gtarted at the time when the vaporized cavity is formed so that the computer does not need to consider vhether hydrodynamic heating vaporizes any more rock. The vaporization radius is calculated from the expression $R_{\mathrm{v}}=\mathrm{CW}^{1 / 3}$ ( $\mathrm{R}_{\mathrm{v}}$ is in $\mathrm{m}, \mathrm{W}$ is in $\mathrm{kt}$ ) where $C=1.9$ for sandstone of density $2.45 \mathrm{gm} /$ $\mathrm{cm}^{3}$. The initial pressure of the cavity gas at the end of the vaporization phase is $1.55 \mathrm{Mb}$.

Figure 3 shows the pressure-volume relationship of the rock used as an aver-

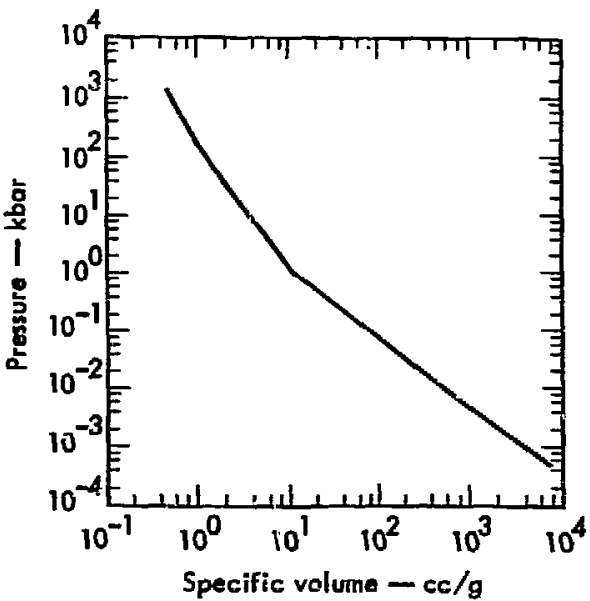

Fig. 2. Cavity gas pressure volume relationship.

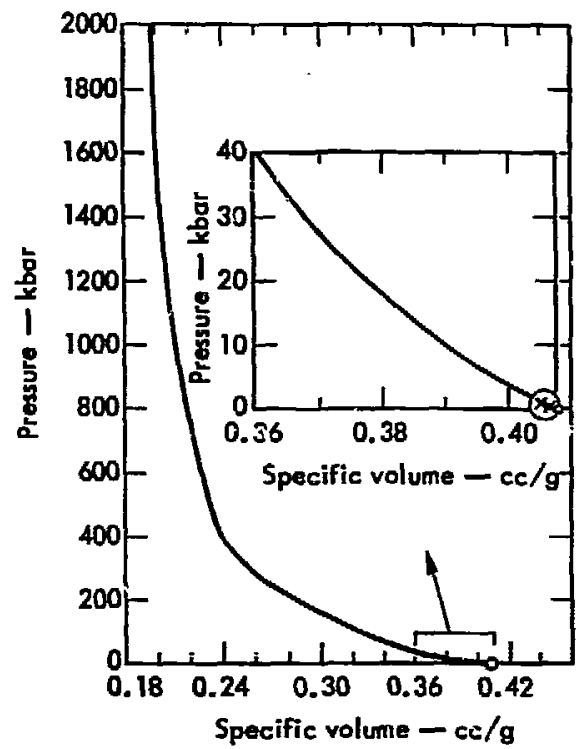

Fig. 3. Pressure - volume relationship for Wagon Theel rock between depths of $9,000 \mathrm{ft}$ to $12,000 \mathrm{ft}$.

age betwreen the depthe of $9,000 \mathrm{ft}$ and $12,000 \mathrm{ft}$. This is based upon both the Hugoniot data and the meagared compressibility of the rock. An average Poisson's 
ratio of 0.2 was selected based on the onedimensional $\mathrm{s}^{\text {t:-ain }}$ tests.

Figure 4 shows the failure criteria used as developed from the shear strength measurements in the form of $K_{b}$ versus $\bar{P}$ as defined below

$$
\begin{aligned}
\bar{P} & =\left(\sigma_{1}+\sigma_{3}\right) / 2 \\
K_{\mathrm{s}} & =\left|\sigma_{1}-\sigma_{3}\right| / 2
\end{aligned}
$$

where $\sigma_{1}$ and $\sigma_{3}$ are the minimum and maximum principal stress respectively. The shear strength curve was extrapolated from $10 \mathrm{kbar}$ of shear strength to $15 \mathrm{kbar}$ and then assumed constant.

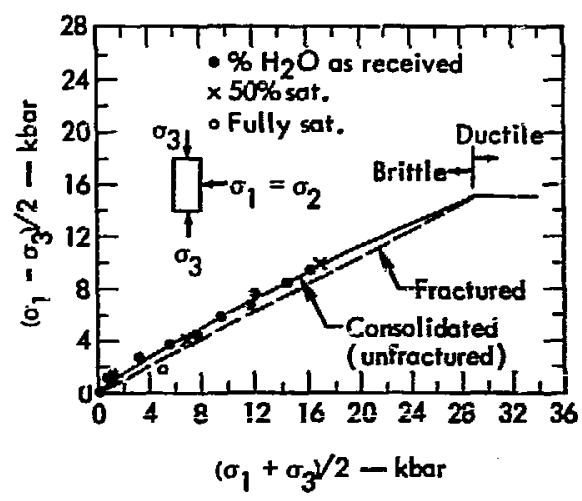

Fig. 4. Shear strength criteria.

\section{Analysis of Previous Nuclear Experiments}

Numerical codes de reloped by Cherry and Pet/: $r s n^{6}$ in conjunction with a compatible material-properties-measurement program developed by Stephens, Schock and Heard $7,8,9$ have led to a reliobie predictive capability for phenomens associated with shock wave propagation. Calculations of cavity radius, peak shock stress particle velocity, and fracture radius associated with chimney height have been confirmed by various experiments. A model or suitable experiment is still required to predict the degree of fracture, the chimney configuration and the permeability increases in the fractured and stressed rock.

The first step in selecting appropriate nuclear experiments is to compare the materials properties measured for Wagon Wheel with those of other experiment6. On the basis of porosity and water content, all experiments in tuff and alluvium and their associated scal- ing laws cen be eliminated from consideration. Eliminating others for a variety of reasons leaves experiments in Nevada Test Site (NTS) granite, Gasbuggy and the Hoggar granite. ${ }^{10}$ Table 2 compares the material equation-of-state (EOS) parameters with Wagon Wheel parameters.

Figure 5 compares the strength curves measured for these media with Wagon Wheel sandstone.

Cherry and Peterson in Ref. 6 present a fairly complete numerical analysis of Hardhat (5 kt in NTS granite) and Gasbuggy (26 +3 in a gas bearing sandstone) verified by experimental measurements. This analysis indicated two types of fracturing which preceed to different radii from the shot point. The first is the limit-of-shear fracture where the rock no longer fails on compressive loading, and the second is the maximum limit fracture where the rock has failed in extension. The fractures are 
Table 2. Material EOS parameters compared with Wagon Wheel parameters.

\begin{tabular}{|c|c|c|c|c|c|c|}
\hline Medium & $\rho_{0}$ & $v_{p}$ & $\sigma$ & $\mathrm{H}_{2} \mathrm{O}$ & $\phi$ & $K \max$ \\
\hline NTS granite & 2.67 & 5.3 & 0.28 & 2 & 1.4 & $2.0 / 7.5^{*}$ \\
\hline P.C. ${ }^{+}$sandstone & 2.5 & 3.5 & 0.3 & 2.7 & $8.0^{*}$ & 3.0 \\
\hline Lewis ${ }^{+}$shale & 2.6 & 3.5 & 0.3 & 1.9 & - & 2.0 \\
\hline Hoggar granite & 2.63 & 5.5 & 0.3 & 0.3 & 0.3 & unk \\
\hline Wagon Wheel sandstone & 2.45 & 4.5 & $0.2^{\mp}$ & 2.0 & $8.0^{*}$ & 15.0 \\
\hline \multicolumn{7}{|c|}{ *Hugoniot elastic limit for NTS granite is 7.5 kbar. } \\
\hline \multicolumn{7}{|c|}{$\rho_{0}=$ initial density $\mathrm{gm} / \mathrm{cc}$} \\
\hline \multicolumn{7}{|c|}{$\begin{aligned} V_{p} & =\text { compressional velocity m/msec } \\
\sigma & =\text { Poisson's ratio }\end{aligned}$} \\
\hline \multicolumn{7}{|c|}{$\mathrm{H}_{2} \mathrm{O}=$ water content by weight $\%$} \\
\hline \multicolumn{7}{|c|}{ Kmas: = maximum shear strength (kbar) } \\
\hline \multicolumn{7}{|c|}{$=8 \%$ porosity and $60 \%$ satusation } \\
\hline \multicolumn{7}{|c|}{$+=$ Gasbuggy } \\
\hline
\end{tabular}

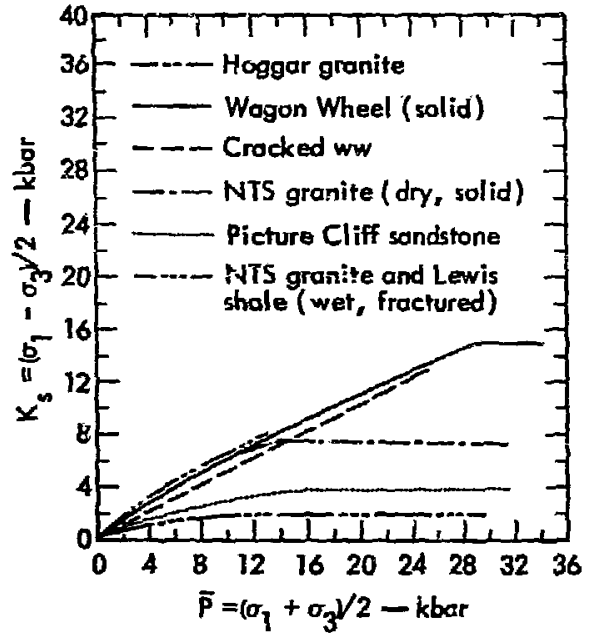

Fig. 5. Media strength curves compared to Wagon Wheel. interconnecting between the carity and the shear fracture radius; this seems to it the boundary of chimney growth. In the second fracture zone, only radial fractures are created.

In terms of strength, fractured wet NTS granite is similar to Gasbuggy sandstone, whereas dry solid NTS and Aoggar ${ }^{10}$ granite is similar to Wagon Wheel sandstone. In granite, the quartz grains are closely packed and allow little rotation or translation of the quartx grains so that the granite deforms elastically until brittle failure occurs. ${ }^{11}$ Even at shear siresses one-balf of the shear strength of granite, microfacturing accurs, resilting in dilatancy which may increase permeability. 
The sandstones, however, b?have quite differently under stress loading. The quartz grains are surcounded by a relatively ductile matrix, allowing them to undergo considerable translation ar: rotation. This cataclastic flow and microfracturing; results in the observed mechanical ductile behavior of the test samples. 12

The difference $i$ the ultimate strerigth between Gasbuggy and Wagon Wheel Rock is attributed to the stronger aatrix coruponents of the sandstone as well as the fact that Wagon Wheel sandstone has more than twice the grain-to-grain contacts per quartz grain as Gasbuggy eandstone. 12

The Wagon Wheel sandstone exhibits dilatancy only near the failure envelope and actually compacts due to shear at lower stress levels. 2 The Wagon Wheel sandstone under one-dimensional triaxial shear tests (representing the shock loading path at low strain rates) will not develop the stress conditions required for failurz. Poisson's ratio under these tests varies from an initial 0.13 at $1 \mathrm{kbar}$ to about 0.3 at 4 kbar of axial stress. ${ }^{2}$ However, at the higher strain rates occurring under shock conditions, the Wagon Wheel sandstone is expected to show considerably less ductile behavior. The shear stress should increase with mean stress with an average Poisson's ratio of 0.2 , intersecting the failure envelope at about $8 \mathrm{kbar}$ of shear stress. This aseumption on the effect of strain rate is supported by the agreement Jetween the calculated ${ }^{6}$ and experimentally verified ${ }^{1}$ permeability increase with distal se for Gasbuggy. The sudden loss of the high distortional energy at these stress levels results in exteneive fracturing. On this basis, the witimaie shear strength be- comes the dominant equation-of-state parameter.

The only nuclear experiments in a medium with shear strength similar to Wagon Wheel are the French detonations in Hoggar granite.

The French experiments in the Hoggar granite prere at low to moderate yieids at depths between 200 to 400 meters. ${ }^{13}$ The scailing laws developed for the media are given below.

- Cavity radius, defined as the interface between the melt and the solid rock.

$R_{c}=7.3 \mathrm{~W}^{1 / 3}$

and also

$R_{c}=\frac{52 W^{1 / 3}}{\left(\rho g h+C_{s}\right)^{1 / 3 \gamma}}$

where

$\gamma=1.03$

$\rho \mathrm{gh}=$ overburder pressure in bars

$\mathrm{C}_{\mathrm{s}}=$ strength term in bars

$120<\mathrm{C}_{\mathrm{s}}<320$

$\mathbf{R}_{\mathrm{c}}=$ Cavity radius in $\mathrm{m}$

$\mathrm{W}=$ Explosive yield in kt

- Radius of crushed zone - between the cavity and this radius the rock hrs been pulverized.

$R_{b}=10 \mathrm{w}^{1 / 3}\left(\mathrm{~m}, \mathrm{kt} \mathrm{t}^{1 / 3}\right)$

also

$1.3 \mathbf{R}_{\mathbf{c}}<\mathbf{R}_{\mathbf{b}}<1.8 \mathbf{R}_{c}$

- Radius of fracture - this radius is also the limit to which the French assumed the chimney will grow and, if consistent with SOC calculaticns, is the maximum extent of shear fracture.

$$
\mathrm{R}_{\mathrm{f}}=26 \mathrm{w}^{1 / 3}\left(\mathrm{~m}, \mathrm{k} \mathrm{t}^{1 / 3}\right)
$$

- Radius of stress zone - this zone is deiined by the drill core fracturing 
in parallel disks; indicating a highly stressed region is being relieved.

Also. some preshot or shock induced fractures are encountered.

$R_{\mathrm{R}}=35 \mathrm{w}^{\mathrm{l} / 3}\left(\mathrm{~m}, \mathrm{kt}^{\mathrm{l} / 3}\right)$

In order to compare the Wagon Wheel rock with the Hoggar granite, a SOC calculation, using the Wagon Wheel EOS, was made for a yield of : $\mathrm{kt}$ with an overburden pressure of 70 bars representing the initial conditions of the Hoggar data. The results are presented in Fig. 3.

Figure 6 shows the cavity radius, limit of compressive failure, fracture initiation and the shock front as a function of time.

The double line at the shock front indicates the width of the shock from maximum acceleration to peak pressure.

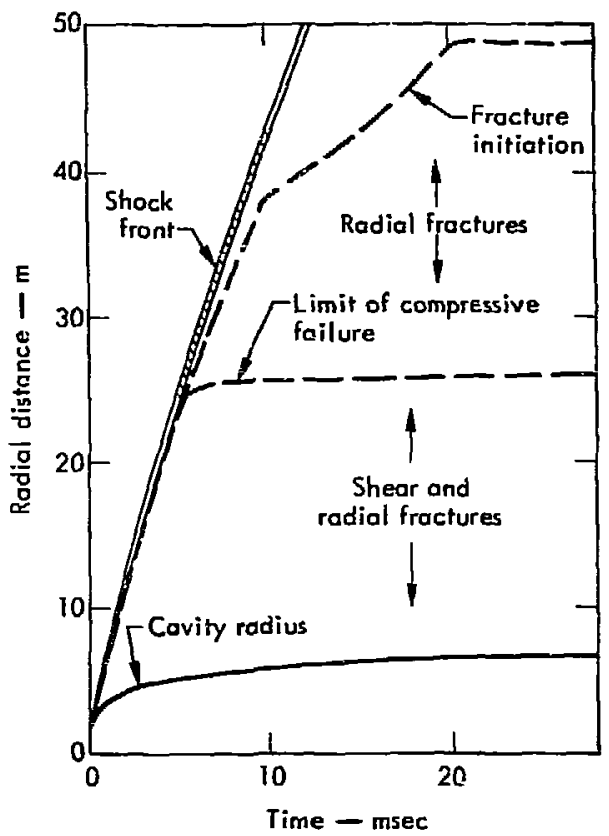

Fig. 6. Cavity radius, limit of compressive failure, fracture initiation, and shock front as a function of time for $1 \mathrm{kt}$.
Table 3. Calculated resuits compared with Hoggar granite experience.

\begin{tabular}{lll}
\hline $\begin{array}{c}\text { Radius } \\
(\mathrm{m})\end{array}$ & Calculation & Hoggar granite \\
\hline$R_{\mathrm{c}}$ & 7.2 & 7.3 \\
$\mathrm{R}_{\mathrm{b}}$ & $10.5-12.0$ & $10.0-14.0$ \\
$\mathrm{R}_{\mathrm{f}}$ & 26.0 & 26.0 \\
$\mathrm{R}_{\mathrm{R}}$ & $38-48$ & 35
\end{tabular}

Table 4. Radius of crush zone determined by comparing crack number for each zone.

\begin{tabular}{|c|c|c|c|}
\hline \multirow{2}{*}{$\begin{array}{c}\text { Zone } \\
\text { number }\end{array}$} & \multicolumn{2}{|c|}{ Crack mumber } & \multirow{2}{*}{$\begin{array}{c}\text { Radial } \\
\text { distance } \\
\text { (m) }\end{array}$} \\
\hline & $\mathrm{T}=\mathbf{2 5 \mathrm { msec }}$ & $T=50 \mathrm{msec}$ & \\
\hline 970 & 1 & 3 & 12.016 \\
\hline 971 & 2 & 5 & 11.744 \\
\hline 972 & 2 & 4 & 11.474 \\
\hline 973 & 2 & 4 & 11.210 \\
\hline 974 & 2 & 4 & 10.949 \\
\hline 975 & 2 & 4 & 10.694 \\
\hline 976 & 3 & 6 & 10.444 \\
\hline 977 & 3 & 6 & 10.200 \\
\hline 978 & 3 & 6 & 9.361 \\
\hline 979 & 3 & 7 & 9.729 \\
\hline 980 & 4 & 8 & 9.504 \\
\hline 981 & 4 & 8 & 9.287 \\
\hline 982 & 4 & 9 & 9.077 \\
\hline 983 & 5 & 10 & B. B76 \\
\hline 984 & 6 & 11 & 8.683 \\
\hline 985 & 8 & 15 & 8.500 \\
\hline 986 & 12 & 19 & 9.328 \\
\hline 987 & 16 & 23 & 8.165 \\
\hline 988 & 18 & 26 & 8.013 \\
\hline 989 & 25 & 33 & 7.873 \\
\hline 990 & 32 & 40 & 7.743 \\
\hline 991 & 49 & 58 & 7.520 \\
\hline 992 & 56 & 64 & 7.343 \\
\hline 993 & 58 & 67 & 7.210 \\
\hline 994 & Melt & Melt & 7.060 \\
\hline 995 & Gas & Gas & 6.123 \\
\hline
\end{tabular}




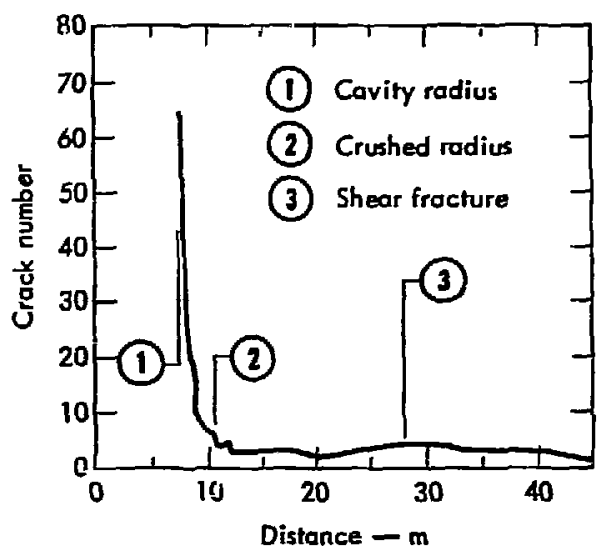

Fig. 7. Crack number as a function of distance.

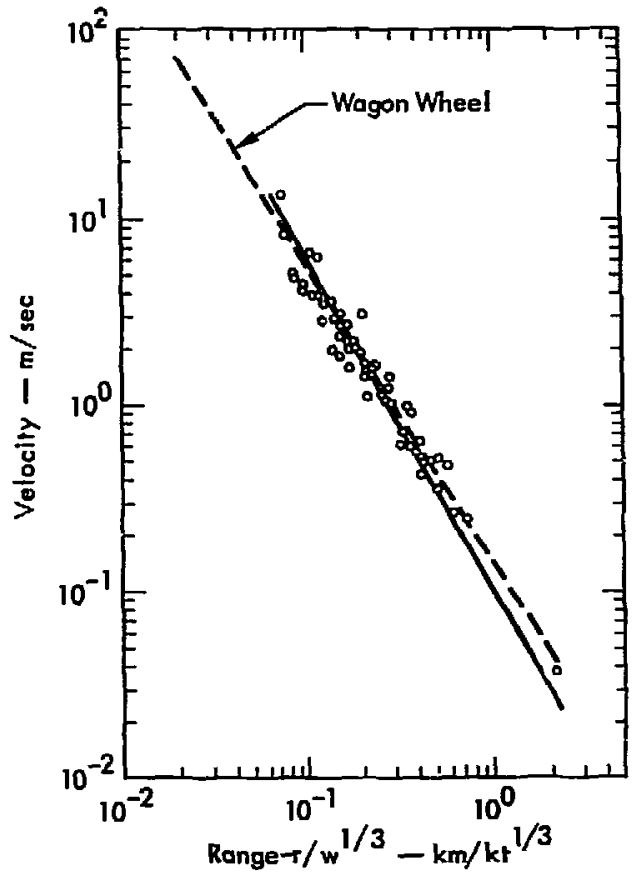

Fig. 8. Particle velocity at shock front vs scaled range comparison with Hoggar granite.

Table 3 compares the calculational results with the Hoggar granite experience.
The radius of the crushed zone was determined by comparing the increase in the crack number for each zone between 25 msec and 50 msec as shown in Table 4. Radial distance is given at the time of 50 msec. The assumption is that the crushed zone was formed by contimued refracture over a period of time. This is further emphasized in Fig. 7 which shows the crack number as a function of distance.

Figure 8 compares the measured peak particle velocity ${ }^{14}$ at the shock front for Hoggar granite with the SOC calculation using the Wagon Wheel EOS. Figure 9 is a comparison of the scaled acceleration.

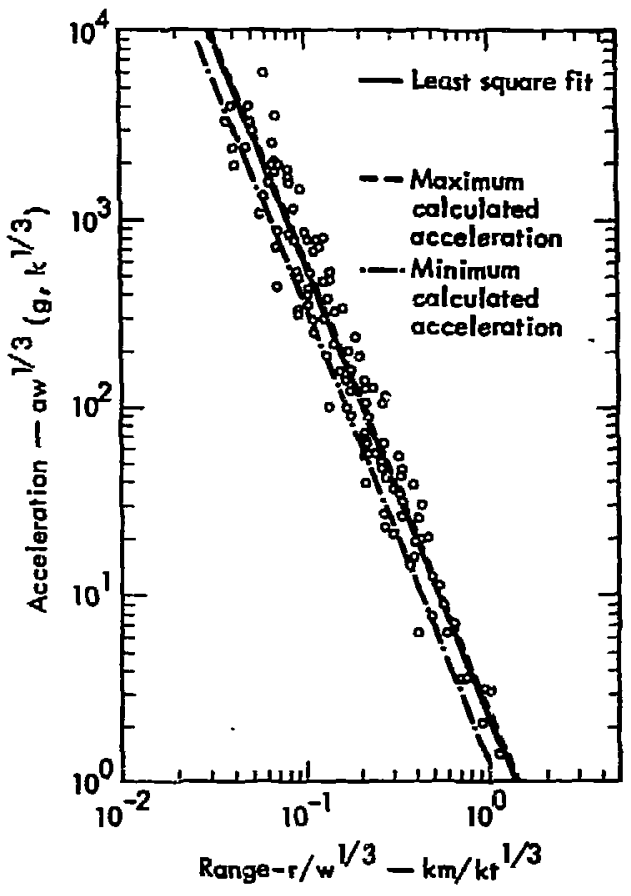

Fig. 9, Scaled acceleration at shock front vs scaled range comparison with Hoggar granite. 
The solid curve in Fig. 9 is a least square fit to the data and also the maximum acceleration at the shock frunt as calculated by SOC. The dashed curve is the SOC peak velocity divided by the rise time to give a minimum pi: :ticle acceleretion. Thus, on the basis of all available data, it geems that the experiments in Hoggar oranite will provide an excellent model for Wagon Wheel.

\section{Numerical Calculations for Wagon Wheel at Depth}

Using a numerical model of stress wave propagation (SOC) ${ }^{6}$ with the material properties just presented, the stressinduced effects on the rock mass were determined at various yields and overhurden fressures for Wagon Wheel. Table 5 compares some of the basic results from these calculations. Calculations 1,4 , and 5 are for depths of $9,600 \mathrm{ft}$. Calculations 2,3 , and 6 are at the overburden pressures of Gasbuggy, Rulison, and French experiments, respectively.
Figures 10 and 11 show the positions of the shock front, initiation of fracture, and cavity radius with respect to time for calculations 4 and 5, respectively. The separation between shear failure on shock loading and extension failure on unloading is clearly defined as the separation of the fracture initiation (limit of fracture) curve from the shock front.

Figures 12, 13 and 14 show the radial stress, shear stress, and velocity, respectively, as a function of distance at the

Table 5. Results of stress-induced effects on rock mass at various yields and overburden pressures.

\begin{tabular}{|c|c|c|c|c|c|c|c|}
\hline Calc & $\underset{\text { (kt) }}{W}$ & $\begin{array}{c}\text { Pove } \\
\text { (kbar) }\end{array}$ & $\begin{array}{l}\mathbf{R}_{\mathrm{y}} \\
\text { (m) }\end{array}$ & $\underset{(\mathbf{m})}{\mathbf{R}_{\mathrm{G}}}$ & $\underset{\text { (kbar) }}{\mathbf{P}_{\mathbf{c}}}$ & $\begin{array}{l}\text { Rsf } \\
\text { (m) }\end{array}$ & $R$ (mx) \\
\hline 1 & 20 & 0.7 & 5.15 & 15.25 & 1.02 & 40 & 78 \\
\hline 2 & 30 & 0.31 & 5.89 & 19.3 & 0.7 & 54 & 118 \\
\hline 3 & 40 & 0.43 & 6.486 & 20.7 & 0.82 & 55 & 125 \\
\hline 4 & 40 & 0.7 & 6.486 & 19.5 & 1.02 & 50 & 101 \\
\hline 5 & 100 & 0.7 & 8.80 & 26.6 & 1.02 & 70 & 139 \\
\hline 6 & 1.0 & 0.07 & 1.896 & 7.2 & 0.47 & 26 & 48 \\
\hline
\end{tabular}

where

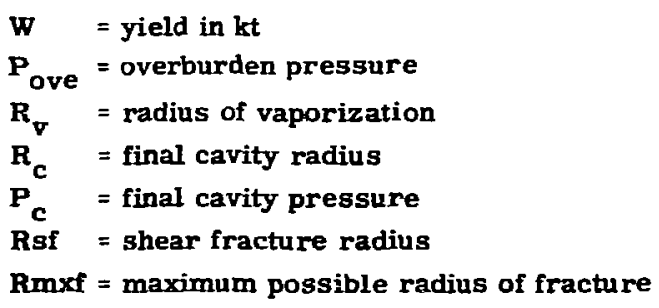




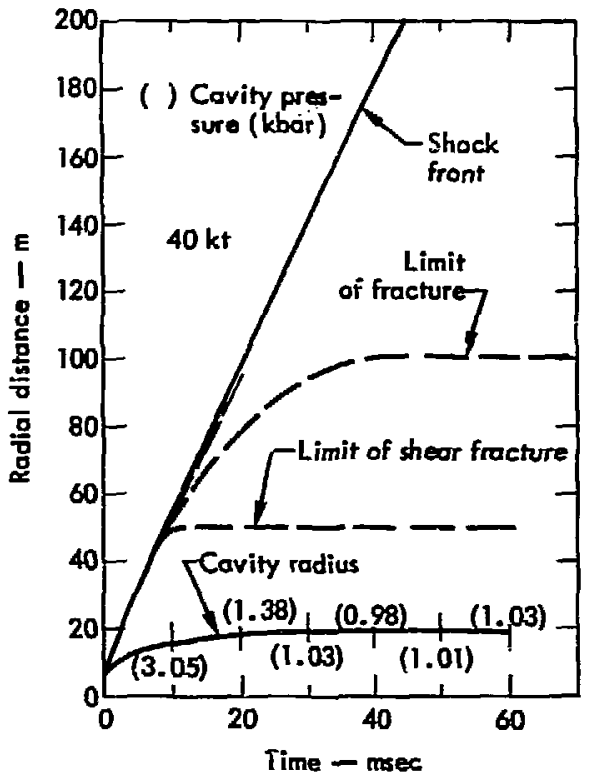

Fig. 10. Radial distance vs tim:? at yield of $\mathbf{4 0} \mathbf{~ k t}$.

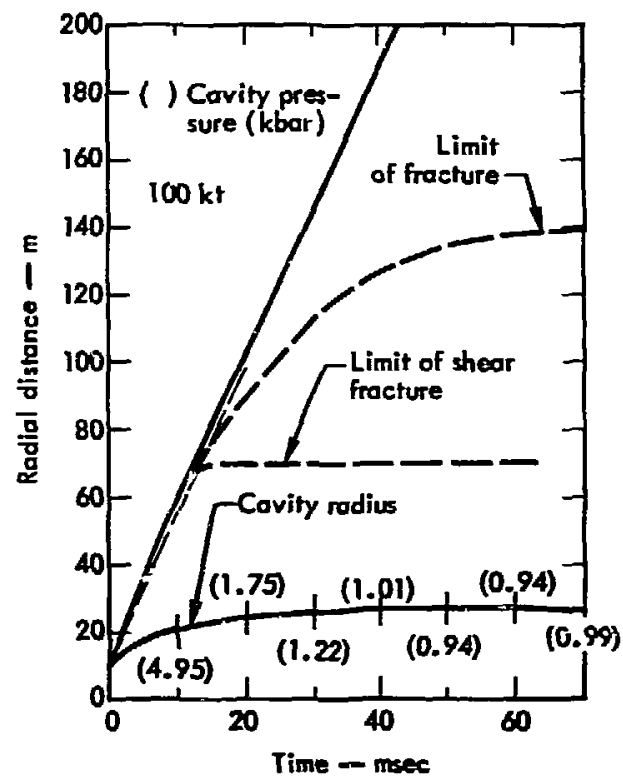

Fig. 11. Radial distance v8 time at yield of $100 \mathrm{kt}$.

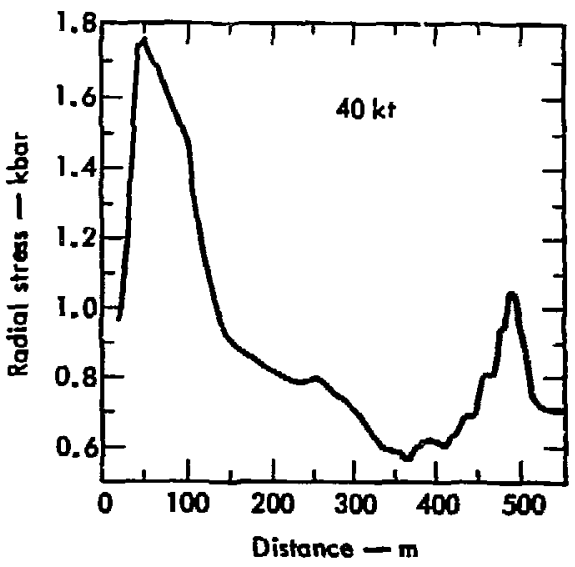

Fig. 12. Radial siress vs radius at $120 \mathrm{~ms}$ at $10,000 \mathrm{ft}$ d.o.b.

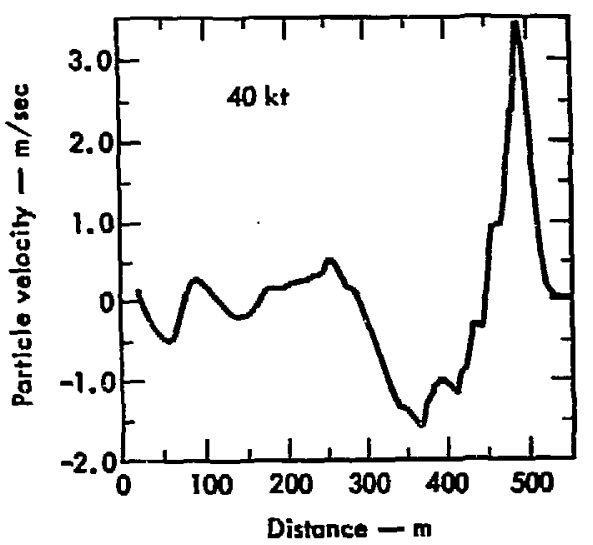

Fig. 13. Particle velocity 88 radius at $120 \mathrm{~ms}$ at $10,000 \mathrm{ft}$ d. o.b.

time the cavity is in quasi-equilibrium for calculation no.4. Between the cavity and the limit of shear fracture radius, the radial stress increases with distance and is the minimum principal stress (i.e., $K_{r \theta}=-\left(\sigma_{\theta}-\sigma_{r}\right) / 2$ is negative $)$, and thus, this is a region where tangential fractures predominate. 


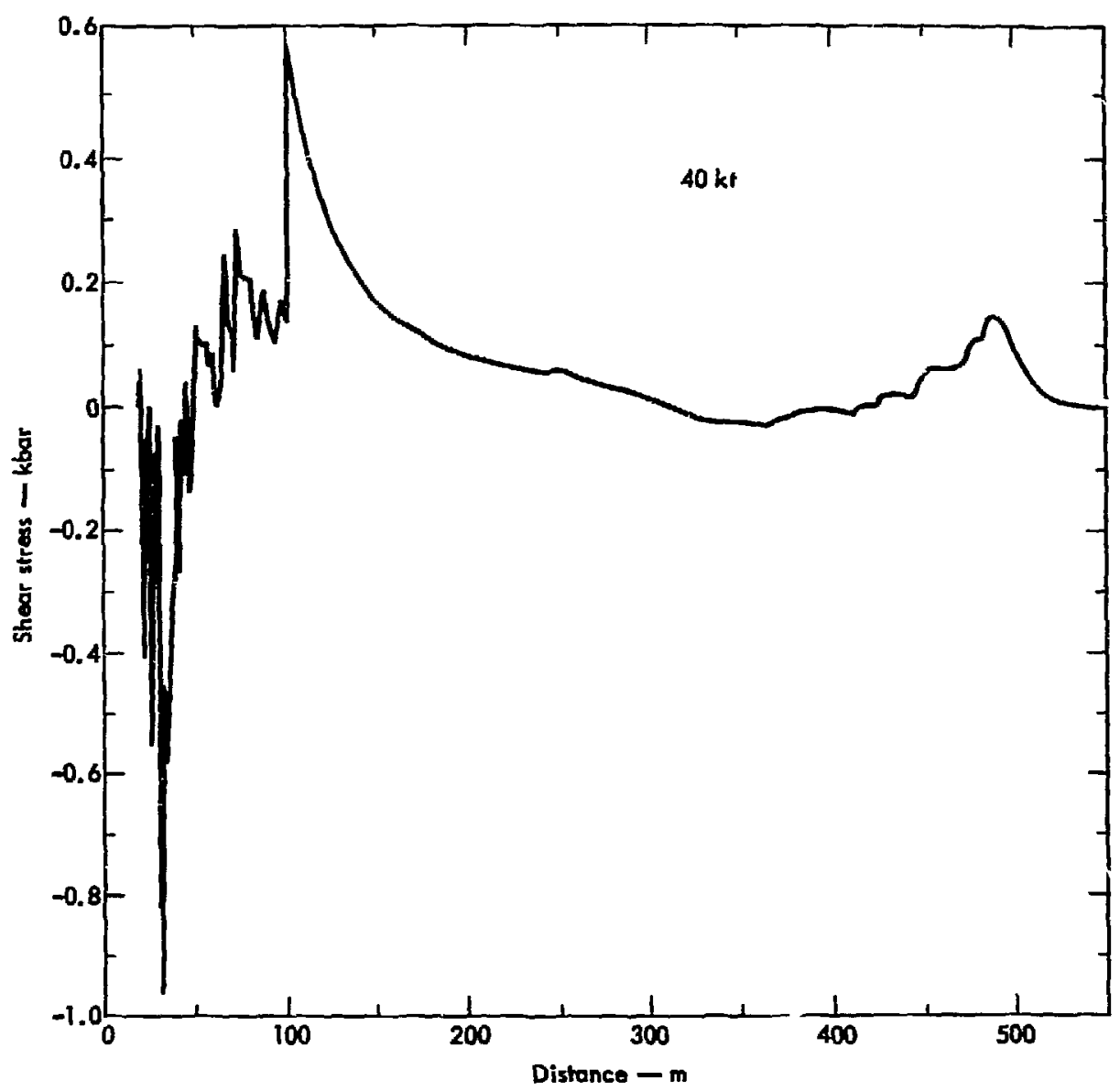

Fig. 14. Shear stress vo radius at $120 \mathrm{~ms}$ at $10,000 \mathrm{ft} d .0 . b$.

Between the limit of shear Iracture and the maximum fracture radius, $K_{T \theta}$ is positive, indicating that the fractures should be radial in this region. Outside the maximum fracture radius, the rock has been stressed but $r$ emains essentially unfractured.
Figure 15 shows the crack number for calculation 4 and 5 as a function of distance horizontally from the shot point. The crack number is the number of times the failure envelope has been exceeded. Corresponding limits of fracture radii are shown, indicating the relative degree of fracture in these zoncs. 


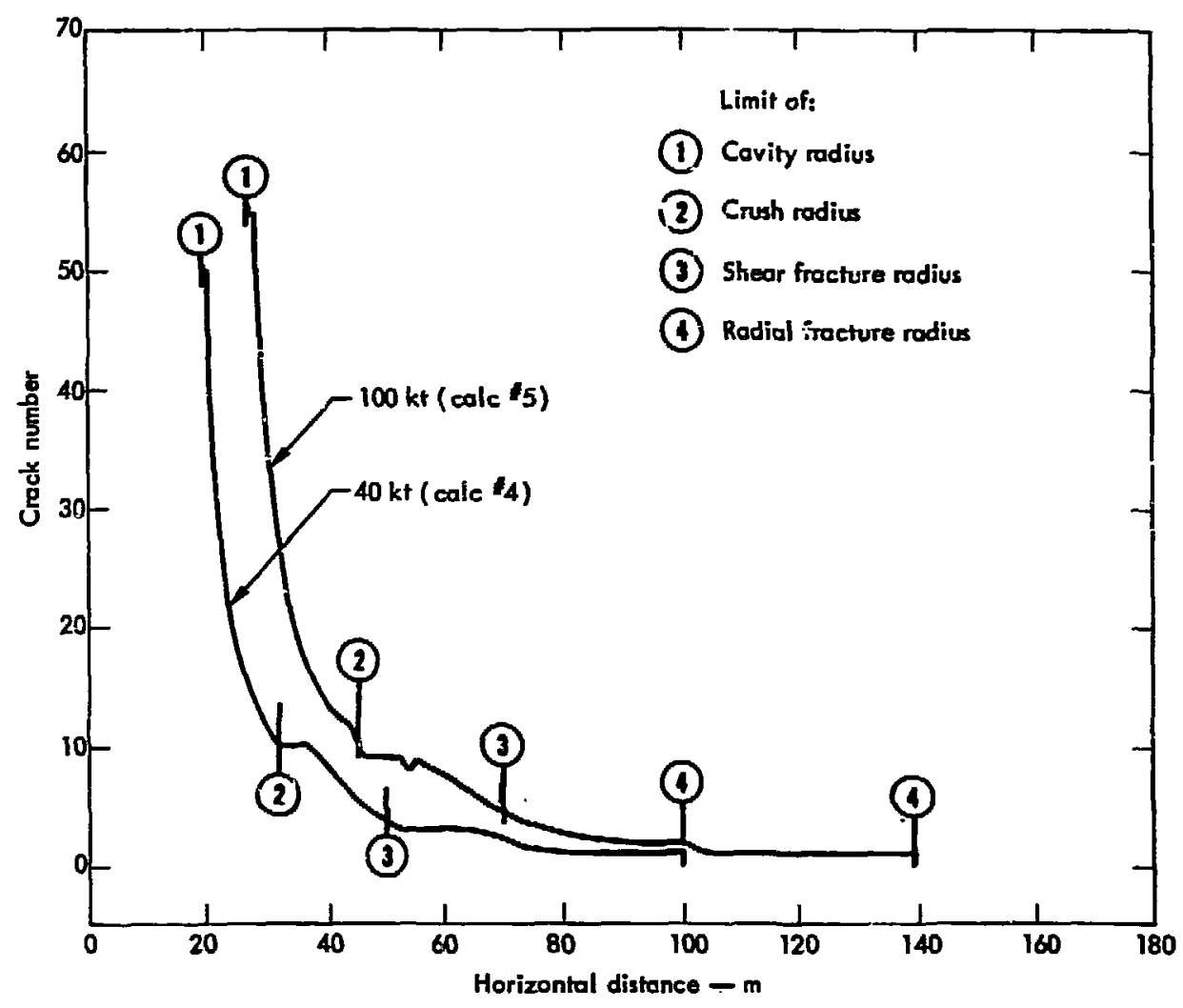

Fig. 15. Crack number for calculations 4 and 5 as a function of distance horizontally from the shot point.

\section{Scaling Laws for Wagon Wheel}

Based on the preceding calculations, the scaling curves for Wagon Wheel were developed as shown in Figs. 16 and 17. Using an adiabatic expansion formulation for the cavity gas as did the French, 15,16 the equation for the cavity radius is

$$
R_{c}=\frac{\alpha P_{v}^{1 / 3 \gamma_{R_{v}}}}{P_{c}^{1 / 3 \gamma}}
$$

where

$*_{\alpha}=1.05$ to account for the melt

$P_{\mathrm{v}}=1.550$ Mbar vaporization pressure

$\gamma=2.3 \quad P>1 \mathrm{kbar}$

$\gamma=1.14 P$ \& $<1$ kbar $\}$ Bee Fig. 2 .

$R_{v}=1.9 \mathrm{w}^{1 / 3}$ radius of vaporization

$\mathbf{P}_{\mathrm{c}}=$ cavity pressure at equilibrium in kbar

Note: The $a$ used by French is baied on shot room void not being vaporized. 


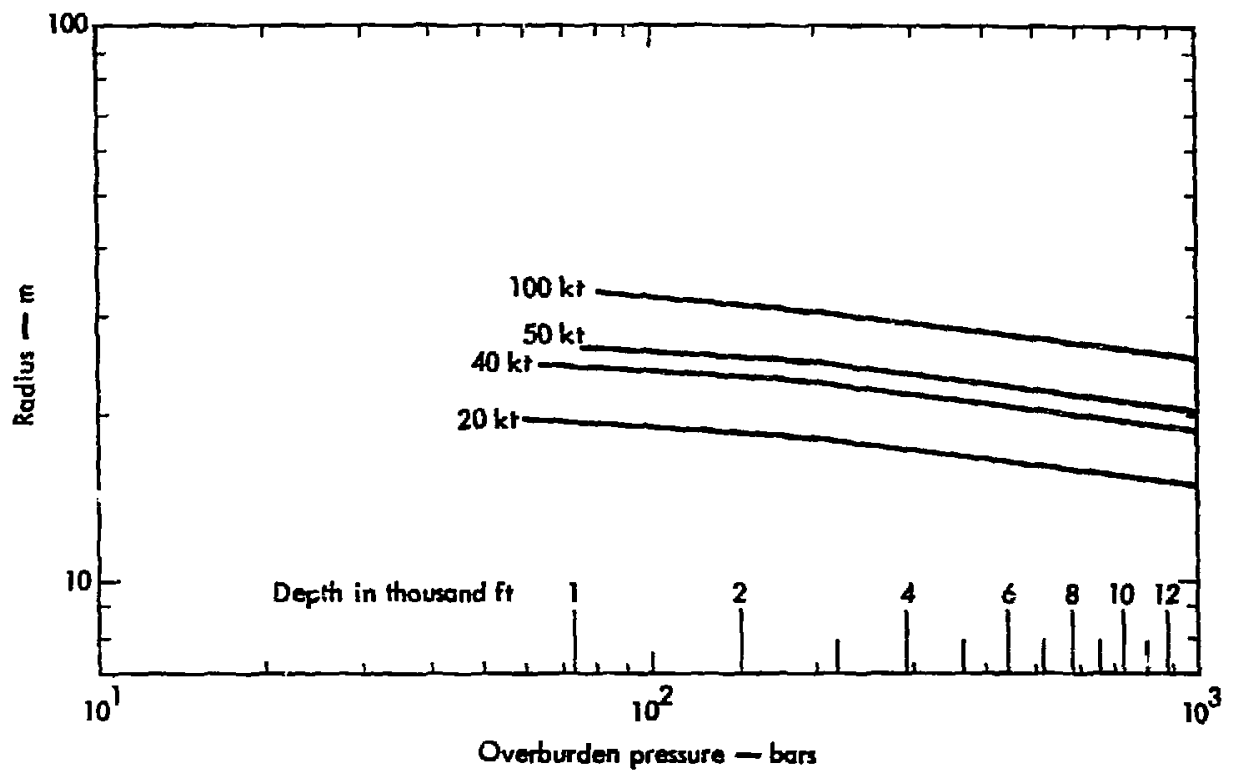

Eug. 16. Cavity radius va overburden.

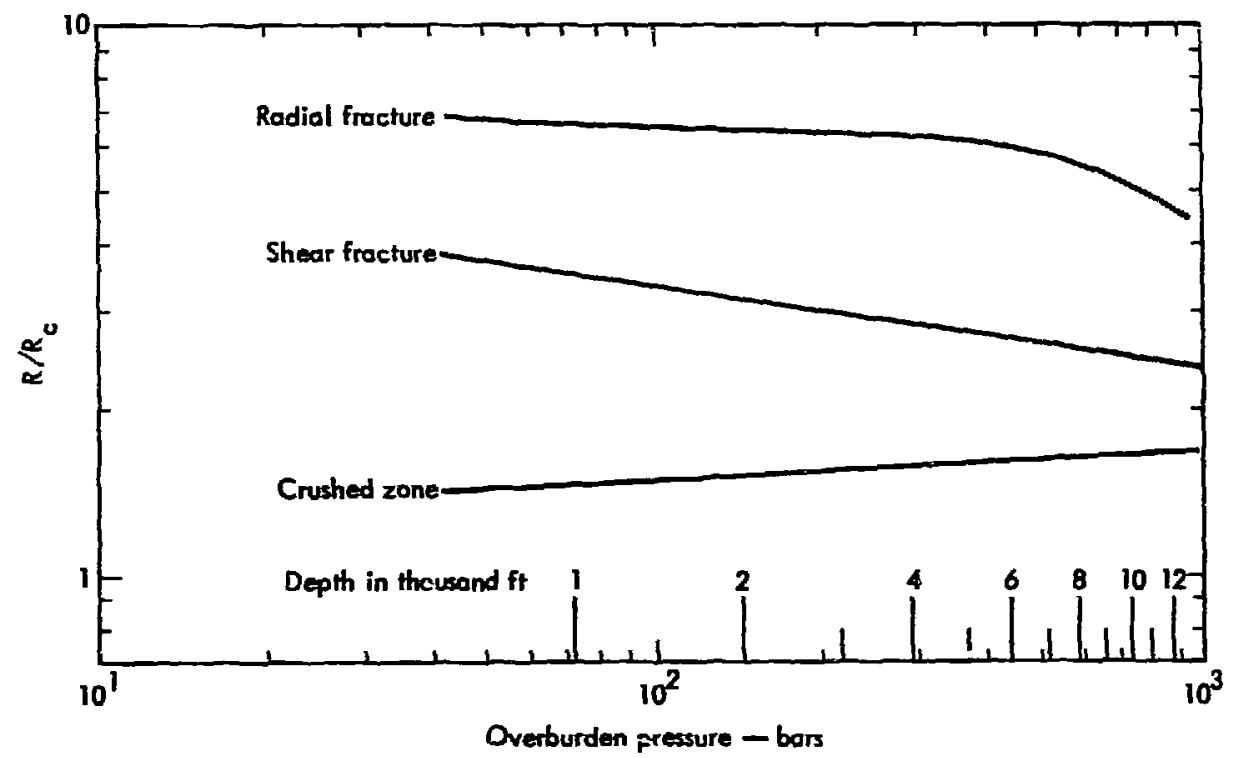

Fig. 17. Ratio of fracture radii to cavity radius vo overburden. 
Doing the arithmetic ricults in

$$
R_{c}=\frac{5.77 W^{1 / 3}}{P_{c}^{1 / 3 \gamma}}
$$

where the distance is expressed in meters and the yield $(W)$ in kilotons.

The cavity presgure is approximately 0.4 kbar greater than the overburden which is the mean strength term for the rock (Table 5), and for pressures less than $1.4 \mathrm{kbar}$, the use of a $\gamma=1.14$ results in errors of less than 5\%. Stbstituting, we have

$$
R_{c}=\frac{5.77 w^{1 / 3}}{(\rho g h+0.4)^{1 / 3.42}}
$$

The difference between this equation and that developed by the French for Hoggar granite is basically in the $\gamma$ assumed for the cavity gas and a slightly smaller atrength term. Figure 16 showB the above equation plotted for 4 yields as a function of overburden fressure.

Figure 17 shows the ratio of the various fracture radil, as determined by the

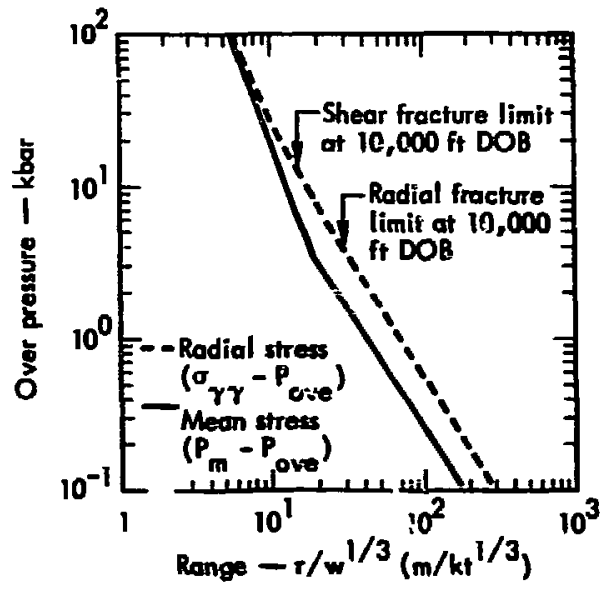

Fig. 18. Wagon Wheel shock stresses vs scaled range.

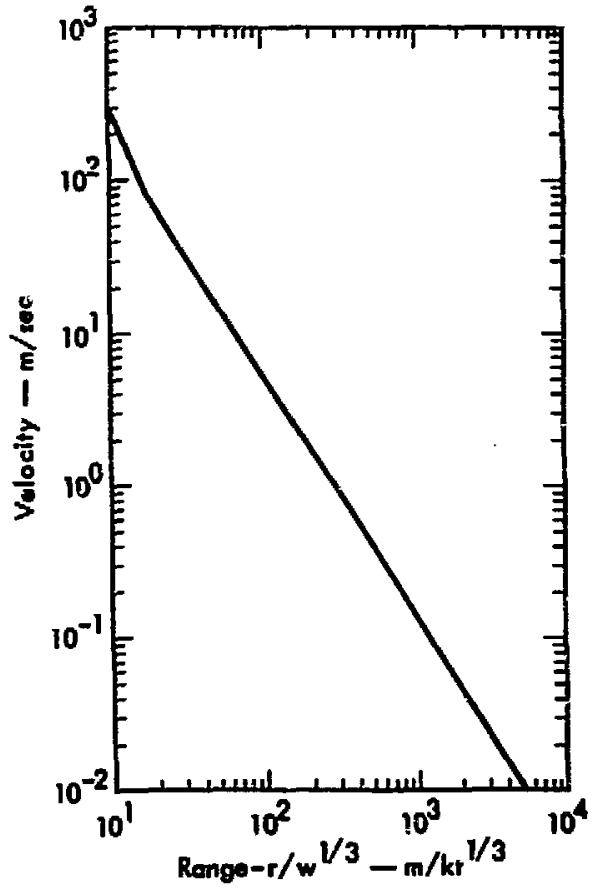

Fig. 19. Peak paxticle velocity v8 scaled range.
SOC calculation, to the cavity radius. The radius of the crushed zone is independent of the overburden preasure, and thus the ratio increages as the cavity radius decreases with depth. The shear fracture radius and radial Iracture radius are atrongly dependent on the overburden pressure, requiring bigher shock stregses to fracture.

Figure 18 ghows the peak overpressure at the shock front as a function of scaled distance where $P_{\text {ove }}$ is the overburden pressure. Figure 19 show the peak particle velocity as a function oi scaled dietance. Figure 20 shows the peak scaled acceleration in gravitational units as a function of scaled distance. 


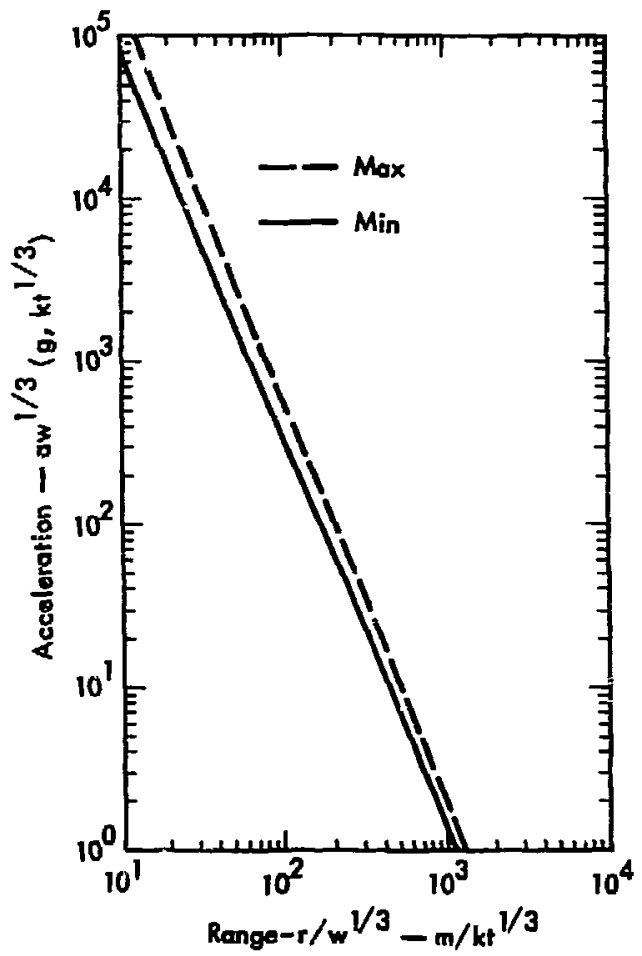

Fig. 20. Scaled acceleration vs scaled range.

\section{Chimney Configuration}

Chimneys observed in Hoggar granite ${ }^{17}$ are of two types. One is asymmetric perpendicular to the bedding with $\mathbf{R}_{\mathbf{c h}}=\mathbf{R}_{\mathbf{c}}$. The other is oval with $R_{c h} \sim 1.4 R_{c}$ about $2 R_{c}$ above the explogion point. Both types do not extend beyond the shear fracture radius. United States experience is similar.

The rock from the site of Gasbuggy has a higher ductile matrix content than that from Wagon Wheel; therefore, it is likely that a chimney will form at Wagon Wheel. The chimney is expected to flare outward with a slope of about $5^{\circ}$. This is intermediate between the two cases in Hoggar granite and is somewhat greater than the U.S. experience. It is based on expected particle siz $\mathrm{e}^{18}$ and experience in rock flow in ore passes. 19,20

Figure 21 shows the expected chimney and associated fracture pattern for a single explosive at $10,000 \mathrm{ft}$ depth. The crushed or pulverized region extends to 1.6 $R_{c}$, the shear fracture to $2.5 R_{c}$ and the maximum radial fracture to $5.1 R_{c}$. The chimney radius measures $1.2 \mathrm{R}_{c}$ at 


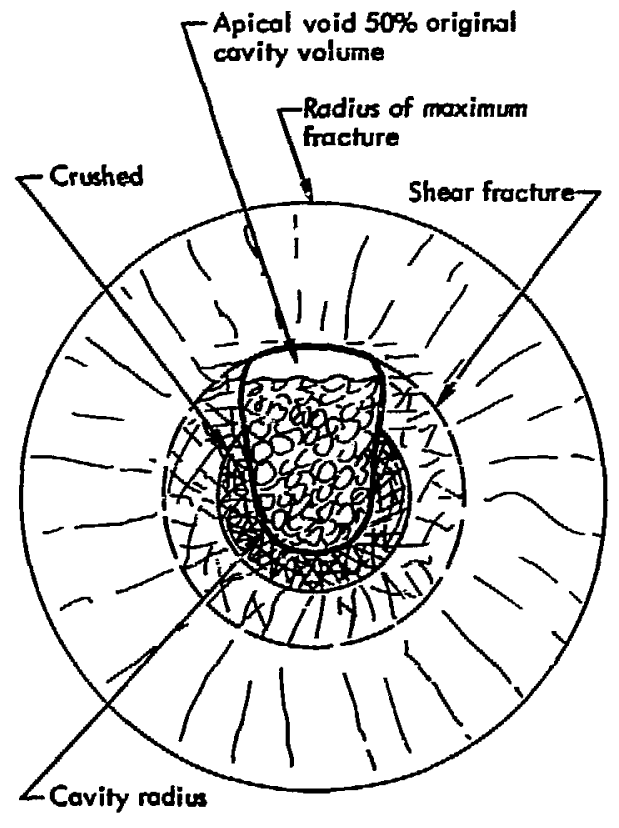

Scale $\longmapsto$ I coitity radius

Fig. 21. Chimney configuration and fracture pattern for Wagon Wheel. an elevation of $2.0 R_{c}$ above the shot point. The total chimney height is $2.5 \mathrm{R}_{\mathrm{c}}$ - Using a porosity of 6.21 for the rubble gives an apical void of 0.5 cavity volumes, and a void height of $0.4 R_{c}$. The maximum chimney height based on a porosity of 0.21 would be $4 R_{c}$ if the chimney were allowed to grow beyond the fracture radius.

Based on permeability measurements in the Hoggar experiments ${ }^{10}$ and gas now test analysis of Gasbuggy, ${ }^{1}$ permeability is expected to be greatly enhaneed within the shear fracture region. In the radial fracture region, permeability is expected to be slightly higher than the initial value, but beyond this no increase is expected as dilatancy argements are not applicable. Static equilibrium of the rock around the chimney requireg that the radial stress adjust from a maximum to a minimum principal stress. This may result in tangential iractures leading to an increase in permeability. This effect would be greatest above the chimney and negligible below.

\section{Multiple Explosive Spacing and Effects}

At present, there are no previous experiments on which to judge or estimate the effects from multiple explosions in the same well bore. Also, no two dimensional calculations have been possible within the time limit of this report. Therefore, the explosive spacing and effects are based on an extrapolation of the onedimensional analygis.

There are two approaches to the timing of the detonations of the explosives, aimultaneous and sequential. Simultaneous as used here means that the explosives are fired within a millisecond of each other. Sequential firing means time delays between detonations greater than several mimites and may be timed until after collapse of the previous chimney.

For Hoggar granite a scaling law on the time of collapse has been developed. 21

$$
t(\min )=1.25 R_{c}-375
$$

where $R_{c}$ ie the cavity radius in meters

for $40 \mathrm{kt}, t=21 \mathrm{~min}$ for $100 \mathrm{kt}, t=29 \mathrm{~min}$. 


\section{SLMULTANEOUS EXPLOSIVE EFFECTS}

The ohock waves from the two explogives will meet at the midpoint between them. The stress conditions on the rock will be almogt identical to a laboratory triaxial test resulting in a fractire pattern parailel to the emplacement hole. As the shocks pass each other, the particle relocity will be reversed and horizontal fractures jevelop and separate. As the shock from one explosive renches the expanding cavity of another, the growth of the cavity alorg the ghot line is temporarily reversed, but normal to the shot line the growth is increased. This should result in elliptical cavities rather than spherical cavities. Rarefaction of the shock of the cavity should be nonexistent in terms of releasing the stress as relatively high pressures will be maintained throughout the entire region between the explosives. At reasonable spacing the cavity should attain 90\% or more of the single explosive volume at the time the shock reaches the cavity. At this time there will be a cylindrical high pregsure region between the cavities with pressures 2 to 3 times the cavity pregsure. This cylindrical pressure will drive the rock radially away from the shot line and vertically into the cavities. The shock interaction effects just described and the degree and the extent horizcntal fractures at the midpoint are dependent on the yield and the spacing of the explosives.

The ahear fracture radius for a single explosive at 10,000 ft is calculated to be $2.5 R_{c}$ where $R_{c}$ is the cavity radius. Therefore, at a spacing of $5 \mathrm{R}_{\mathrm{c}}$ the shear fracture regions will be tangent. From Fig. 18 the stress versus distance for fracturing can be estimated, assuming converging shock atregees will be additive. On this basis, the mavimum explosive spacing which will leave contimously shear tractured rock between detonation points may be estimater to be $7 \mathbf{R}_{\mathrm{c}}$.

Figure 22 shows the ratio of height stimulated to the cavity radius as a function of the number of explosives and spacing.

\section{SEQUENTIAL EXPLOSIVE EFFECTS}

Sequential firing of explosives arranged in a vertical array allows the use of larger individual yields with less total yield to reduce the possivility of seismic damage.

When the first explosive is detonated, a chimney, shear fracture and stressed region is formed as shown in Fig- 21. The rock in the stressed region above the chimney is in an unstabl- .ress state and in the process of readjustment due to formation of the chimney. Because of this stressed condition, the effective shear strength of the rock is reduced.

The second explosive, detonated some distance above the first chimney, propagates a shock wave which refractures the prestressed region and reflects off the existing chimney as a tensile wave. Figure 23 shows the relative effect on the particle velocity of the shock and tensile waves midway between the second explosive and the lower chimney top. This velocity is also compared with the velocity profile of a particle in the horizontal plane of the second explosive. The particle vilocity in location 1 (Fig. 23) increases rapidly under shock loading, then decays due to the high shear stresses. The reflected tensile wave from the chimney increases the velocity again as it passes, spalling 


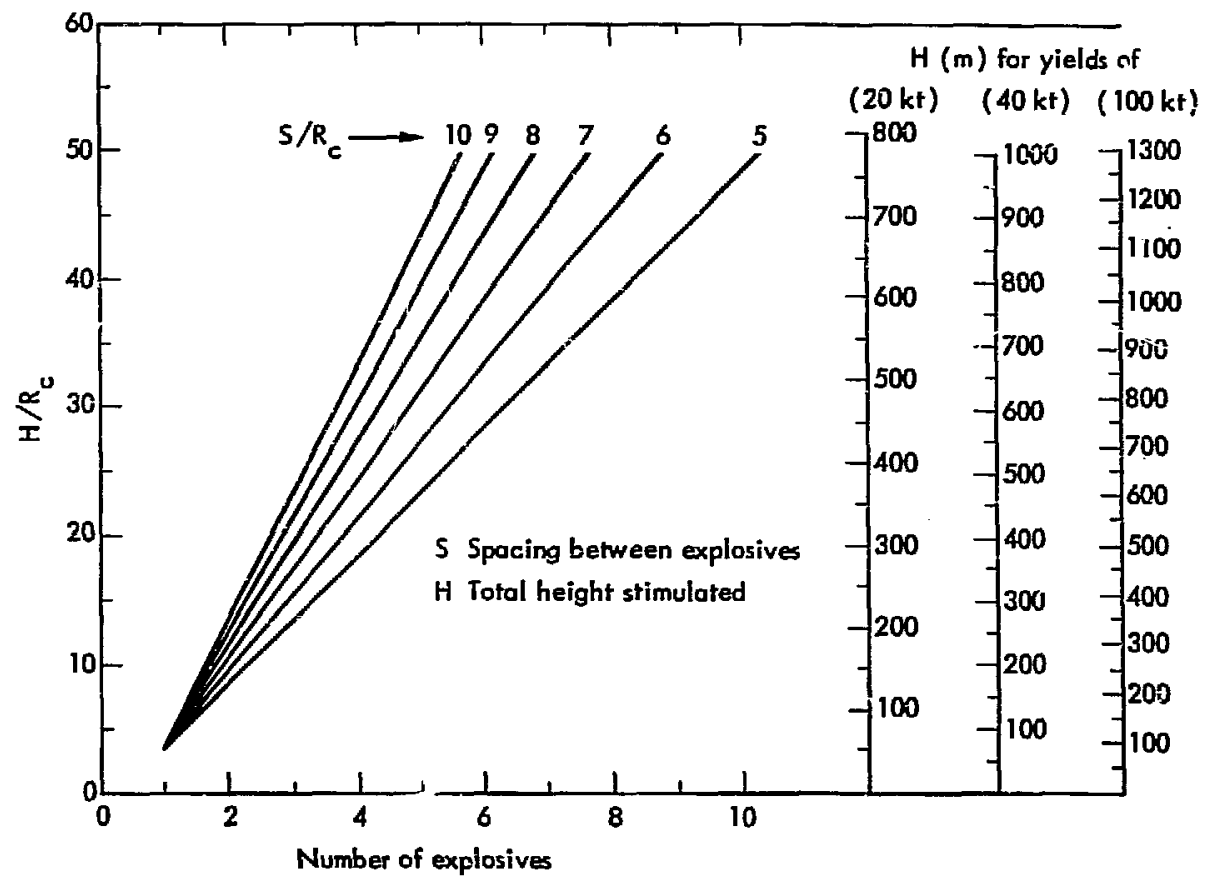

Fig. 22. Ratio of height stimulated to cavity radius as function of the number of explosions and spacing.

the rock. The cavity created by the secund explosion is in a quasi-equilibrium state at the time the reflected tensile wave reaches it. The cavity pressure then drives the rock below the cavity formed by the second detonation down into the lower chimney void, shearing along the cylindrical zone which has previously been weakened by the tensile wave. The logical analysis of the phenomena shock, spall, and gas acceleration is based on analysis of cratering experiments. ${ }^{22}$ The relative magnitude of each effect depends on yield of the second explosive and on the distance between this explosive and the free surface of the existing chimney.

Overburden pressures are minimal in cratering experiments, resulting in large

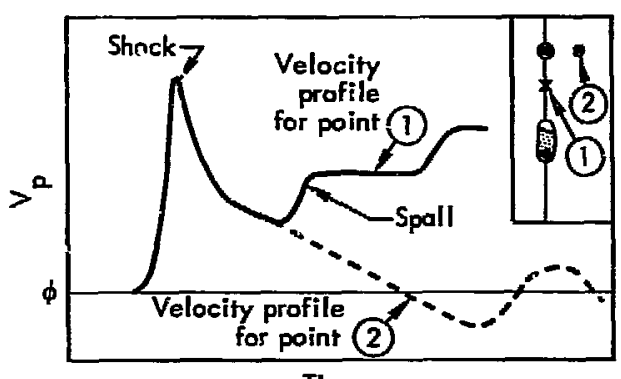

Fig. 23. Velocity profile b-tween multiples fired sequentially.

spall effects and gas drive pressures of as much as 200 bars. For overburden pressures at $10,000 \mathrm{ft}$ depth, velocity enhancernent from spall would be severely reduced and confined to a cylindrical region 


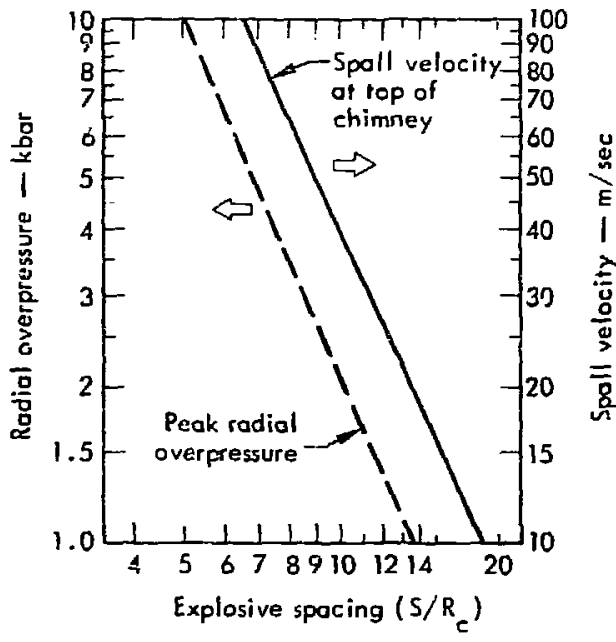

Fig. 24. Spall fffects as function of explosive spacing.

abou the axis connecting the two explosives. However, cavity pressures will equalize at about I kbar.providing considerable enhancement of ine gas acceleration nhase.

Peak surface velocity measurernents made on cratering experiments indicate that surface velocities of $34 \mathrm{~m} / \mathrm{sec}$ or greater are sufficient to form craters, and velocities of $24 \mathrm{~m} / \mathrm{sec}$ are sufficient to form retarcs. ${ }^{23}$ These velocities cusespond to scaled distances between the explosive and the free surface of $51 \mathrm{~m} / \mathrm{w}^{1 / 3}$ and $61 \mathrm{~m} / \mathrm{w}^{1 / 3}$, respectively $\left(\mathrm{m} / \mathrm{kt}^{1 / 3}\right)$.
Figure 24 shows the peak spall veloci:y and radial overpressure at the upper surface of the chimney resulting from the first detonation as a function of the initial sparing of the explosives, assuming a chimney height of $2.5 \mathbf{R}_{\mathrm{c}}$.

On this basis, for Wagcn Wheel sandstone, explosive spacing up to $12.5 \mathrm{R}_{c}$ is expected to produce a conimuous chimney. However, it should be noted here that there is a possibility that the assumptions regarding the chimney produced by the first detonation may not be confirmed. That is, upon the detonation of the first explosion an appreciably shorter chimney may be formed than has been previously assumed, or the chimney which does form may be completely filled with debris, and display no apical void. In either of these cases, the effective reflection of the shock wave from the first chimney toward the region around the second explosive will be significantly less than for the optimum first chimney configuration.

This, then argues for a somewhat closer spacing between the two explosives to present a higher probability of complete collapse in the inter-explosive region. Thus, it is recommended that the explosive spacing be maintained between $7.5 R_{c}$ and $10 \mathbf{R}_{c}$ for Wagon Wheel.

\section{Summary}

Laboratory tests and studies of the Wagon Wheel sandstone developed the behavior characteristics of the rock under stress loading. The similarity of the shear strength between Wagon Wheel sandstone and Hoggar granite and the resulting nu- niericai calculation of the shock induced effects measured on the experiments in Hoggar granite, provided a degree of confidence in the calculations for Wagon Wheel at depth. It also provided a model for chimney configuration. At a depth of 
$10,000 \mathrm{ft}$, the chimney radius should be

$1.2 \mathrm{R}_{\mathrm{c}}$ and the height of the chimney should be 2.5 $R_{c}$ above the shot point with an apical void at the top. A radius of increased permeability extends to $2.5 R_{c}$ from the ahot point.

With the above model and confidence in the equation-of-state measurements and the calculations based on those measurements, it was possible to deduce the interaction processes for multiple explosives in the same well bore.

This resulted in a spacing of the explosives of $5 \mathrm{R}_{c}$ to $7 \mathrm{R}_{\mathrm{c}}$ for simultaneous and $7.5 R_{c}$ to $12.5 R_{c}$ for sequential detonation.

\section{Acknowledgments}

Review and comments by Fred Holzer, Gary Higgins, John Toman and Howard Tewes on the initial draft were especially helpful. Discussions with Ted Cherry (continuum mechanics), Bob Schock, Hugh Heard and Doug Stephens (equation-of- state measurements), and especially (ris Borg (mineralogy and microfracture) not only provided me with the necessary data but also an education. Special thanks also to Fran Peterson for her computer help and Marian Nicholas for typing. 
1. R. Lemon, El Paso Natural Gas Co., private communication (1970).

2. R. Shock, D. Stephens, and H. Heard, Wagon Wheel EOS, Lawrence Radiation Laboratory, Livermore, Rept. UCRL-50963 (1970).

3. Terra-Tek, inc. Testing Program conducted for El Paso Natural Gas Co., (Salt Lake City, Utah, 197G).

4. Leroy Hord, Law rence Radiation Laboratory, Livermore, private communication (1970).

5. T. R. Butkovich, The Gas Equation of State for Natural Materials, Lawrence Radiation Laboratory, Livermore, Rept. UCRL-14729 (1967).

6. J. T. Cherry and F. L. Petersen, "Numerical Simulation of Stress Wave Propagation from Underground Nuclear Explosions," in Proc. Am. Nucl Soc. Topical Meeting-Engr. With Nucl. Expl. (Las Vegas, Nevada).

7. D. R. Stephens and E. M. Lilley, "Loading and Unloading Pressure-Volıme Curves for Rocks," in Proc. Am. Nucl. Soc. Topical Meeting-Engr. With Nucl. Expl. (Las Vegas, Nevada).

8. R. N. Schock, "Dynamic-Elastic Moduli of Rock Under Pressure," in Proc. Am. Nucl. Soc. Topical Meeting-Engr. With Nucl. Expl. (Las Vegas, Nevada).

9. H. C. Heard, "The Influence of Environment on the Inelastic Behavior of Rocks," in Proc. Am. Nucl. Soc. Topical Meeting-Engr. With Nucl. Expl. (Las Vegas, Nevada).

10. S. Derlich, "Underground Nuclear Explosion Effects in Granite Rock Fracturing," in Proc. Am. Nucl. Soc. Topical Meeting-Engr. With Nucl. Expl. (Las Vegas, Nevada).

11. 1. Y. Borg. Microfracturing in Postshot Gasbuggy Core GB-3, Lawrence Radiation Laboratory, Livermore, Rept. UCRL-50893 (1970).

12. I. Y. Borg. Microscopic Examination of Undeformed and Laboratory Deformed Wagon Wheel Rocks, Lawrence Radiation Laboratory, Livermore, Internal Rept. SDK7 1-1.

13. C. E. Chapin, Lawrence Radiation Laboratory, Livermore. private communication (1970).

14. L. Michaud, "Effets Mecaniques au Dela de la Zone Proche d'ene Explosion Nucleaire Souterraine dans le Granite," in Peaceful Nuclear Explosives Phenomenology and Status Report 1970, International Atomic Energy Association, Vienna, Rept. P1-388 (1970).

15. F. Deloit and F. Supiot, "Nuclear Stimulation of Oil Reservoirs," in Proc. Am. Nucl. Soc. Topical Meeting-Engr. With Nucl. Expl. (Las Vegas, Nevada).

16. L. Michaud, Explosions Nusleaires Souterrains Etude Des Rayons De Cavity. Commissariat a l' E'nergy Atomique, Bruyeres-le-Chatel, Rept. CEA-R-3594. 
17. S. Derlich, Study of a Chimney Created by Underground Nuclear Explosions. French Atomic Energy Rept. CEA-R-3851 (English trans.: Lawrence Radiation Laboratory, Livermore, UCRL-Trans-10449).

18. T. Sterrett, Drilling Investigation of the Lower Part of the Pile-Driver Cavity. Lawrence Radiation Laboratory, Livermore, Rept. UCRL-50765 (1969).

19. R. Kvapil, "Gravity Flow of Gramular Materials in Hoppers and Bins in Mines-II Coarse Materials," Int. J. Rock Mech, Mining Sci. 2, 277-304 (1965).

20. H. Winterhorn, Shear Resistarce and Equation-of-State for Moncohesive, Gramular Macromeritic Systems, Princeton Soil Engineering Research Series 17, Report 43 (1966).

21. F. Duclaux, S. Derlich, J. Faure, H. Ferrieux, and M. Perrier, "Liaigon Bntre le Rayon et la Durée d'Existence des Cavitiés Crés par les Tirs Nuclégires Souterrains:" C. R. Acad, Sc. Paris, 264, 496-497 (1967).

22. R. Terbune, T. Stubbs, and J. T. Cherry. "Nuclear Cratering on a Digital Compater," Am. Nucl. Soc. (Jamuary 14-16, 1970 ).

23. J. Toman, Project Buggy: A Nuclear Bow Excavation Experiment, Lavrence Radiation Laloratory, Livermore, Rept. UCRL-71280. 